\title{
Perioperative changes in respiratory impedance in lobectomy and their clinical impact
}

\author{
Ryosuke Kaku ${ }^{1}$, Makoto Yoden ${ }^{1}$, Takuya Shiratori ${ }^{1}$, Kazuki Hayashi ${ }^{1}$, Keigo Okamoto ${ }^{1}$, Yasuhiko Oshio ${ }^{1}$, \\ Yasutaka Nakano ${ }^{2}$, Jun Hanaoka ${ }^{1}$ \\ ${ }^{1}$ Division of General Thoracic Surgery, Department of Surgery, Shiga University of Medical Science, Shiga, Japan; ${ }^{2}$ Division of Respiratory \\ Medicine, Department of Internal Medicine, Shiga University of Medical Science, Shiga, Japan \\ Contributions: (I) Conception and design: R Kaku; (II) Administrative support: J Hanaoka; (III) Provision of study materials or patients: All authors; (IV) \\ Collection and assembly of data: R Kaku, M Yoden; (V) Data analysis and interpretation: R Kaku, J Hanaoka; (VI) Manuscript writing: All authors; (VII) \\ Final approval of manuscript: All authors. \\ Correspondence to: Ryosuke Kaku, MD. Division of General Thoracic Surgery, Department of Surgery, Shiga University of Medical Science, Seta \\ Tsukinowa-cho, Otsu, Shiga 520-2192, Japan. Email: kakutin@belle.shiga-med.ac.jp.
}

Background: Respiratory function declines after lung resection. However, perioperative changes in respiratory impedance and their clinical significance are unclear. The forced oscillation technique can measure respiratory impedance during quiet breathing and possibly early after surgery. We investigated respiratory impedance changes before and after lung lobectomy and examined the correlation of impedance with clinical factors.

Methods: We prospectively included patients who underwent lobectomy between February 2018 and March 2020 and measured respiratory impedance by forced oscillation preoperatively and postoperative days 1 and 7. We statistically analyzed changes in perioperative forced oscillation measurements and their correlation with clinical factors, including subjective symptoms. The modified British Medical Research Council scale and the chronic obstructive pulmonary disease (COPD) assessment test were used for scoring subjective symptoms.

Results: Forty-four subjects were included, in whom respiratory impedance could be measured from postoperative day 1 . The respective mean values for forced oscillation measurements preoperatively and at postoperative days 1 and 7 were as follows: respiratory resistance, $5 \mathrm{~Hz}: 2.28,2.77$, and 2.75; respiratory resistance, $20 \mathrm{~Hz}: 2.00,2.36$, and 2.32; difference in respiratory resistance at 5 and $20 \mathrm{~Hz}: 0.28,0.40$, and 0.43 ; respiratory reactance, $5 \mathrm{~Hz}:-0.31,-0.65$, and -0.56 ; resonant frequency: $7.45,10.41$, and 9.81; and low-frequency reactance area: $1.33,3.27$, and 2.84. These changes were statistically significant $(\mathrm{P}<0.01)$. Besides the difference in respiratory resistance at 5 and $20 \mathrm{~Hz}$, all other measurements on postoperative day 7 were relatively weakly correlated with the modified Medical Research Council scale score at this time point (all $\mathrm{P}<0.05)$. Respiratory complications correlated with the respiratory resistance difference, respiratory reactance, and resonant frequency on day $7(\mathrm{R}=0.415,-0.421$, and 0.441$)$, while the latter also correlated with postoperative hypoxemia on day $1(\mathrm{R}=0.433)$.

Conclusions: Respiratory impedance was measurable even early after surgery and significantly changed postoperatively. As the sample size was small and appeared to be biased, assessing respiratory impedance and clinical factors in detail was difficult. Since respiratory impedance is suggested to be associated with clinical factors that affect the postoperative course, it is necessary to accumulate cases and observe them over longer periods.

Keywords: Respiration; impedance; lobectomy; hypoxemia; forced oscillation

Submitted Oct 22, 2020. Accepted for publication Dec 30, 2020.

doi: $10.21037 /$ jtd-20-3090

View this article at: http://dx.doi.org/10.21037/jtd-20-3090 


\section{Introduction}

Pulmonary function declines after lung surgery. However, this is difficult to assess with spirometry because it requires the patient's maximum exhalation effort, which is hindered early after surgery due to pain, cough, and sputum. The forced oscillation technique (FOT) is a non-invasive method for measuring lung mechanics (1) and can be applied even in patients with difficulty with spirometry.

In the FOT, respiratory impedance ( $\mathrm{Zrs})$ is measured by the airflow and pressure returning from the periphery of the lung when the forced oscillation is applied from the mouth. Zrs is expressed using respiratory resistance (Rrs) and respiratory reactance $(\mathrm{Xrs})$ as follows: $(\mathrm{Zrs})^{2}=(\mathrm{Rrs})^{2}+$ $(\mathrm{Xrs})^{2}$. Rrs corresponds to the viscous resistance and mainly reflects airway resistance (Raw), whereas Xrs corresponds to elasticity and inertia and reflects the lung stiffness and the difficulty of air entering the lungs $(1,2)$. Some consider that Rrs at $5 \mathrm{~Hz}$ (R5) represents total Raw, that Rrs at $20 \mathrm{~Hz}$ (R20) represents central Raw, and that the difference between R5 and R20 (R5-R20) represents peripheral Raw $(3,4)$; however, there is no physiological basis for these considerations (1). R5-R20 is only a frequency dependence of Rrs. The point at which Xrs $=0$ is referred to as resonant frequency (Fres) and the integral of Xrs at $5 \mathrm{~Hz}$ (X5) to the Fres is referred to as the low-frequency reactance area (ALX). X5, Fres, and ALX are frequently used as a representative marker of Xrs (1). Previous studies have reported that R5, R5-R20, and Fres are higher, and X5 is lower in patients with obstructive pulmonary ventilation disorders such as asthma and chronic obstructive pulmonary disease (COPD) than in healthy controls $(5,6)$. In addition, R20 was found to be most important in the severity of asthma, poor control, quality of life, and exacerbation frequency (7). Another study suggested Fres as a marker of lung fibrosis in patients with interstitial lung disease $(8,9)$.

MostGraph 02 (Chest M.I., Inc., Tokyo, Japan) can measure Rrs and Xrs in a moment during tidal breathing and may be performed even early after surgery. However, it is unclear how the measurement of $\mathrm{Zrs}$ changes before and after lung surgery and whether the measurement of Zrs itself is meaningful for postoperative care. This study aimed to clarify Zrs changes in lobectomy and determine the clinical relevance of this measurement. We hoped that if adverse events such as respiratory failure and pneumonia could be predicted and detected early after surgery by assessing Zrs, it would be possible to prevent exacerbations and provide early intervention.
Therefore, in this study, we revealed changes in Zrs during the perioperative period of lobectomy and investigated the correlation of $\mathrm{Zrs}$ in the pre- and postoperative periods with various clinical factors, such as physical characteristics, comorbidities, length of surgery, intraoperative blood loss, postoperative complications, and subjective symptoms. We present the following article in accordance with the STROBE reporting checklist (available at http://dx.doi.org/10.21037/jtd-20-3090).

\section{Methods}

\section{Patients}

In this prospective observational study, 57 consecutive patients scheduled to undergo radical lobectomy for non-small cell lung cancer (NSCLC) between February 2018 and March 2020 were recruited after providing informed consent. The principal investigator or the research coordinator was responsible for maintaining the respondents' anonymity. The study was conducted in accordance with the Declaration of Helsinki (as revised in 2013). The study was approved by the ethics board of Shiga University of Medical Science (NO.: R2017-185; December $25,2017)$ and written informed consent was obtained from each participant.

Patients who were not indicated for lobectomy, those who had difficulty in preoperative MostGraph measurements, those who had a history of lung surgery, or those who required bilobectomy or total pneumonectomy were excluded from the study.

\section{Surgical procedures and perioperative management}

Thoracotomy or thoracoscopic surgery was performed. In cases without a preoperative diagnosis, needle biopsy or pulmonary wedge resection was performed during surgery, followed by radical lobectomy and lymph node dissection if a definitive diagnosis of lung cancer was obtained by intraoperative rapid pathological examination. At the end of the surgery, two drains were placed in the thoracic cavity to observe bleeding and air leakage and were subsequently removed after postoperative day 1 (POD1). For pain, epidural anesthesia or intravenous patientcontrolled analgesia was performed; oral administration of acetaminophen and non-steroidal anti-inflammatory drugs was started from POD1, and only oral analgesics were taken after removal of the chest drain. 


\section{Measurement of Zrs}

R5, R20, R5-R20, X5, Fres, and ALX were measured before the operation and at PODs 1 and 7, and the values were compared. Measurements were performed using MostGraph 02 (Chest M.I., Inc., Tokyo, Japan) as follows. In the sitting position, with the neck in a comfortable neutral posture and wearing a nose clip, the subjects supported their cheeks to eliminate upper airway shunting during the measurements. The examiner confirmed the respiratory waveform during measurement and selected the one with the lowest R5 out of three series with stable waveforms.

\section{Subjective symptoms}

We used the modified British Medical Research Council (mMRC) scale and the COPD assessment test (CAT) as scales of subjective symptoms (10-14). Dyspnea on exertion was evaluated by mMRC on a scale of 5 , from 0 to 4 . Although CAT is used for scoring the respiratory status of patients with COPD from 0 to 5 points by evaluating eight items, we used three items, i.e., cough, sputum, and dyspnea, which can be evaluated during hospitalization, as the modified CAT (mCAT).

\section{Data collection}

Clinical factors were defined as follows: subjective symptoms (mMRC and mCAT scores), preoperative factors [age, sex, height, weight, Brinkman Index (B.I.), clinical stage, induction therapy, medical history, and preoperative spirometry measurements], perioperative factors (thoracotomy approach, excision cite, number of resection segments, length of surgery, blood loss, weight gain rate, duration of the chest drainage, postoperative hospital stay, and pathological stage), and postoperative complications. Stage was determined using the 8th edition of TNM classification for lung cancer (15). The number of resection segments was calculated as five segments in the left upper lobe. Postoperative complications were evaluated by the Common Terminology Criteria for Adverse Events (CTCAE) version 5.0 (16).

\section{Statistical analysis}

All results are expressed as mean \pm standard deviation (SD). Statistical analysis was performed using SPSS version 22 (SPSS Inc., Chicago, IL, USA). Perioperative R5, R20,
R5-R20, X5, Fres, and ALX were tested for normality by the Shapiro-Wilk test. For normally distributed variables, the parametric paired $t$-test was used to obtain statistically significant differences in changes in these variables before and after the operation. For non-normally distributed variables, the non-parametric Wilcoxon signed-rank test was used.

The correlation between the measured Zrs and mMRC score was examined by Spearman's rank correlation test, while the correlation with clinical factors other than the mMRC score was tested by Pearson's correlation analysis. $\mathrm{P}$ values $<0.05$ were considered as statistically significant.

\section{Subgroup analysis}

We enrolled patients without respiratory disease into the control group, and patients with a history of COPD, interstitial pneumonia (IP), and combined pulmonary fibrosis and emphysema (CPFE) into subgroups, and compared Zrs measurements at each time point.

Normally distributed variables were tested for homoscedasticity with the Levene test. One-way ANOVA was used for homoscedastic distributed variables to obtain statistically significant differences in subgroups at each time point. For non-homoscedastic distributed variables, Welch's $t$-test was performed; for non-normally distributed variables, the Kruskal-Wallis test was used.

We similarly divided the surgical procedure into subgroups comprising video-assisted thoracic surgery (VATS) and thoracotomy and compared the measured Zrs values at each measurement time point. The independent $t$-test was used for normally distributed variables, and Welch's $t$-test was used for non-normally distributed variables to obtain a significant difference.

\section{Results}

The study included 57 patients who provided consent to participate. From a total of 11 patients without lung cancer who were diagnosed with benign illnesses by intraoperative rapid pathological examination, one declined to participate in the study after surgery, and one was discharged on POD6. These patients were consequently excluded from the study. Thus, 44 patients (35 male, 9 female; age: mean \pm SD, $69.2 \pm 10.3$ years) were included in the analysis (table online: https://cdn.amegroups.cn/static/public/jtd-20-3090-1.xlsx).

Rrs and Xrs were measurable by MostGraph on POD1 in all 44 patients analyzed. 
Table 1 Preoperative factors

\begin{tabular}{|c|c|}
\hline Preoperative factors & $\mathrm{N}(\%)$ or mean $\pm \mathrm{SD}$ \\
\hline $\mathrm{N}$ & 44 \\
\hline Age (years) & $69.2 \pm 10.3$ \\
\hline Sex (male/female) & $35(79.5) / 9(20.5)$ \\
\hline Height (cm) & $165.0 \pm 8.0$ \\
\hline Body weight (kg) & $62.4 \pm 8.1$ \\
\hline Smoker & $34(77.3)$ \\
\hline Current-/ex-/never smoker & $2(4.5) / 32(72.7) / 10(22.7)$ \\
\hline Brinkman index & $628.0 \pm 618.6$ \\
\hline Clinical stage & 44 \\
\hline IA1 & $9(20.5)$ \\
\hline IA2 & $17(38.6)$ \\
\hline IA3 & $5(11.4)$ \\
\hline IB & $4(9.1)$ \\
\hline IIA & None \\
\hline IIB & $4(9.1)$ \\
\hline IIIA & $5(11.4)$ \\
\hline Induction therapy & None \\
\hline Preoperative comorbidity & $38(86.4)$ \\
\hline Respiratory disease & $19(43.2)$ \\
\hline COPD & $11(25.0)$ \\
\hline IP & $5(11.4)$ \\
\hline CPFE & $3(6.8)$ \\
\hline Cardiovascular disease & $26(59.1)$ \\
\hline Ischemic heart disease & $5(11.4)$ \\
\hline Arrhythmia & $5(11.4)$ \\
\hline Hypertension & $21(47.8)$ \\
\hline Diabetes & $5(11.4)$ \\
\hline Others & $27(61.4)$ \\
\hline \multicolumn{2}{|l|}{ Spirometry parameters } \\
\hline $\mathrm{VC}(\mathrm{mL})$ & $3,546.8 \pm 653.6$ \\
\hline$\%$ VC (\%) & $103.0 \pm 12.1$ \\
\hline $\mathrm{FEV}_{1.0}(\mathrm{~mL})$ & $2,538.0 \pm 559.8$ \\
\hline$\% \mathrm{FEV}_{1.0}(\%)$ & $94.8 \pm 15.6$ \\
\hline $\mathrm{FEV}_{1.0} \%(\%)$ & $73.1 \pm 10.1$ \\
\hline
\end{tabular}

Values are presented as frequency (\%) or mean \pm standard deviation (SD). SD, standard deviation; COPD, chronic obstructive pulmonary disease; IP, interstitial pneumonia; CPFE, combined pulmonary fibrosis and emphysema; VC, vital capacity; \%VC, measured vital capacity/predicted vital capacity $\times 100$; $\mathrm{FEV}_{1.0}$, forced expiratory volume in 1 second; $\mathrm{FEV}_{1.0} \%$, forced expiratory volume $\%$ in 1 second; $\% \mathrm{FEV}_{1.0}$, measured forced expiratory volume in 1 second/predicted forced expiratory volume in 1 second $\times 100$.
The preoperative clinical factors are shown in Table 1 . Thirty-four patients $(77.3 \%)$ had a history of smoking, and the mean B.I. was $628.0 \pm 618$.6. Thirty-nine patients had preoperative comorbidity, and $19(43.2 \%)$ had respiratory diseases; of the latter, 11 (25.0\%) had COPD, 5 (11.4\%) had IP, and $3(6.8 \%)$ had combined pulmonary fibrosis and emphysema. Moreover, 35 patients were at clinical stage 1, accounting for $79.5 \%$ of the study participants.

Perioperative factors assessed during the present study are illustrated in Table 2. The surgical approach included VATS in 38 patients $(86.4 \%)$ and thoracotomy in 6 patients (13.6\%). Right upper lobectomy was the most common surgery (16 patients, $36.4 \%$ ). The mean length of surgery was $299.0 \pm 74.6 \mathrm{~min}$, and the mean bleeding volume was $87.9 \pm 141.7 \mathrm{~mL}$. The mean length of postoperative hospital stays was $9.9 \pm 4.5$ days. Most patients were in the early pathological stage (36 were at stage 1,4 were at stage 2 , and 4 were at stage 3$)$. Postoperative complications of all CTCAE grades were observed in 30 patients $(68.2 \%)$, with atelectasis being the most common (18 patients, $40.9 \%$ ), followed by coughing requiring antitussive drugs (15 patients, $34.1 \%)$. Postoperative complications of CTCAE grade 2 and 3 were observed in 11 patients (25.0\%) and $1(2.3 \%)$ patient, respectively. Among these, CTCAE grade 2 or higher respiratory complications was observed in 8 patients (18.2\%), as follows: pneumonia in 3 patients $(6.8 \%)$, hypoxemia in $4(9.1 \%)$, atelectasis requiring bronchoscopy in $1(2.3 \%)$, and prolonged pulmonary fistula in $1(2.3 \%)$ patient.

\section{Perioperative changes in Zrs}

Changes in FOT measurements before and after surgery are shown in Figure 1 and Table 3. The mean values of all FOT measurements changed significantly at POD1 and POD7 compared to the respective preoperative values. Specifically, R5, R20, R5-R20, Fres, and ALX significantly increased, whereas $\mathrm{X} 5$ significantly decreased postoperatively $(\mathrm{P}<0.05)$. From POD1 to POD7, only the mean value of $\mathrm{X} 5$ improved significantly $(\mathrm{P}=0.018)$.

In the subgroup analysis of respiratory disease, at most time points, there was no significant difference in FOT measurements between the subgroups, but there was a significant difference in X5, Fres, and ALX on POD1 $(\mathrm{P}=0.035,0.045$, and 0.034 , respectively; Figure 2$)$.

In the subgroup analysis of the surgical procedure, there was no significant difference at any time point for any measurement. 
Table 2 Perioperative factors

\begin{tabular}{|c|c|}
\hline Perioperative factors & $\mathrm{N}(\%)$ or mean $\pm \mathrm{SD}$ \\
\hline VATS/thoracotomy & $38(86.4) / 6(13.6)$ \\
\hline \multicolumn{2}{|l|}{ Excision site } \\
\hline RUL & $16(36.4)$ \\
\hline RML & $2(4.5)$ \\
\hline RLL & $9(20.5)$ \\
\hline LUL & $11(25.0)$ \\
\hline LLL & $6(13.6)$ \\
\hline Length of surgery (min) & $299.0 \pm 74.6$ \\
\hline Blood loss (mL) & $87.9 \pm 141.7$ \\
\hline Body weight change rate (POD1) (\%) & $1.65 \pm 1.27$ \\
\hline Body weight change rate (POD7) (\%) & $-0.21 \pm 1.87$ \\
\hline Postoperative hospital stay & $9.9 \pm 4.5$ \\
\hline Duration of the chest drainage & $2.8 \pm 3.2$ \\
\hline \multicolumn{2}{|l|}{ Pathological stage } \\
\hline IA1 & $8(18.2)$ \\
\hline IA2 & $17(38.6)$ \\
\hline IA3 & $3(6.8)$ \\
\hline IB & $8(18.2)$ \\
\hline IIA & None \\
\hline IIB & $4(9.1)$ \\
\hline IIIA & $4(9.1)$ \\
\hline Postoperative complications & $30(68.2)$ \\
\hline Respiratory complications & $23(52.3)$ \\
\hline Pneumonia & $3(6.8)$ \\
\hline \multirow[t]{2}{*}{ Atelectasis (with/without BF) } & $18(40.9)$ \\
\hline & {$[1(2.3) / 17(38.6)]$} \\
\hline Sputum (need to take expectorants) & $6(13.6)$ \\
\hline Hypoxemia (HOT) & $4(9.1)$ \\
\hline Cough (need to take antitussives) & $15(34.1)$ \\
\hline Cardiovascular complications & $6(13.6)$ \\
\hline Ischemic heart disease & None \\
\hline Arrhythmia & $5(11.4)$ \\
\hline Thrombosis & $1(2.3)$ \\
\hline Technical complications & $4(9.1)$ \\
\hline Prolonged pulmonary fistula & $1(2.3)$ \\
\hline
\end{tabular}

Table 2 (continued)
Table 2 (continued)

\begin{tabular}{cc}
\hline Perioperative factors & N (\%) or mean \pm SD \\
\hline Chylothorax & $1(2.3)$ \\
Recurrent laryngeal nerve palsy & $2(4.5)$ \\
Others & $3(6.8)$ \\
Postoperative death & None \\
\hline
\end{tabular}

SD, standard deviation; VATS, video-assisted thoracic surgery; VC, vital capacity; LLL, left lower lobe; LUL, left upper lobe; $\mathrm{RLL}$, right lower lobe; RML, right middle lobe; RUL, right upper lobe; BF, bronchofiberoscopy; HOT, home oxygen therapy.

\section{Perioperative changes in subjective symptoms}

Changes in mMRC and mCAT scores before and after surgery are shown in Figure 3. Preoperatively, 36 (81.8\%) patients scored 0 on the mMRC scale, and $8(18.2 \%)$ scored 1. On POD1, 2 (4.5\%) patients scored 0, 20 (45.5\%) scored 1, $12(27.3 \%)$ scored 2, $6(13.6 \%)$ scored 3, and $4(9.1 \%)$ scored 4. On POD7, 13 (29.5\%) scored 0, 23 (52.3\%) scored 1, $6(13.6 \%)$ scored 2, $1(2.3 \%)$ scored 3, and 1 $(2.3 \%)$ scored 4 . The mean mMRC score significantly increased from $0.18 \pm 0.39$ preoperatively to $1.77 \pm 1.05$ on POD1 $(\mathrm{P}=0.000)$ and $0.95 \pm 0.86$ on POD7 $(\mathrm{P}=0.000)$. A significant change was also noted from POD1 to POD7 $(\mathrm{P}=0.000)$ (Figure 3).

The mean mCAT score significantly increased from $1.86 \pm 2.13$ preoperatively to $4.30 \pm 2.38$ and $3.98 \pm 2.54$ on POD1 and POD7, respectively (both $\mathrm{P}=0.000$ ). No improvement was noted from POD1 to POD7 ( $\mathrm{P}=0.417)$ (Figure 3).

\section{Correlation between Zrs and clinical factors}

\section{Subjective symptoms}

On POD7, R5, R20, X5, Fres, and ALX relatively weakly correlated with the corresponding $\mathrm{mMRC}$ score at this time point $\left(r_{S}=0.315,0.304,-0.299,0.314\right.$, and 0.324$)$, but no other significant correlation was observed.

\section{Other factors}

Table 4 shows the statistically significant correlations between Zrs and clinical factors. Preoperative factors correlating with Zrs included age, sex, height, smoking history, B.I., and spirometry parameters [vital capacity (VC), $\% \mathrm{VC}$, forced expiratory volume during the first second 
$\mathrm{R} 5\left(\mathrm{cmH}_{2} \mathrm{O} / \mathrm{L} / \mathrm{s}\right)$

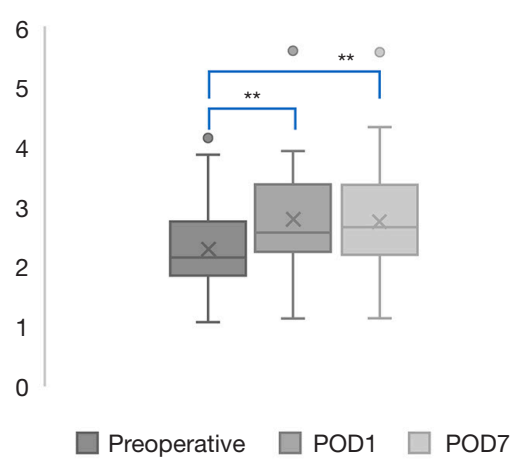

$\mathrm{R} 20\left(\mathrm{cmH}_{2} \mathrm{O} / \mathrm{L} / \mathrm{s}\right)$

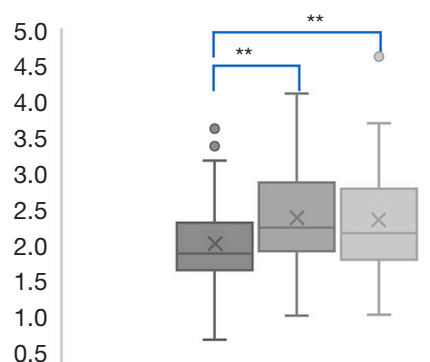

Preoperative
$\mathrm{R} 5-\mathrm{R} 20\left(\mathrm{cmH}_{2} \mathrm{O} / \mathrm{L} / \mathrm{s}\right)$

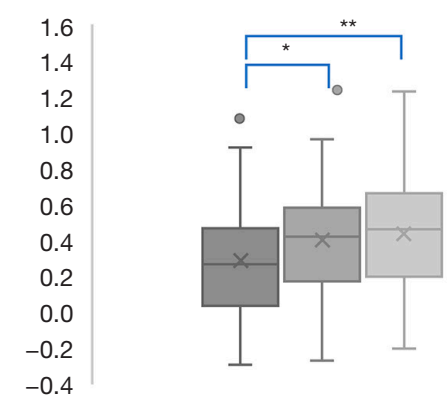

$\square$ Preoperative $\square$ POD1 $\square$ POD7
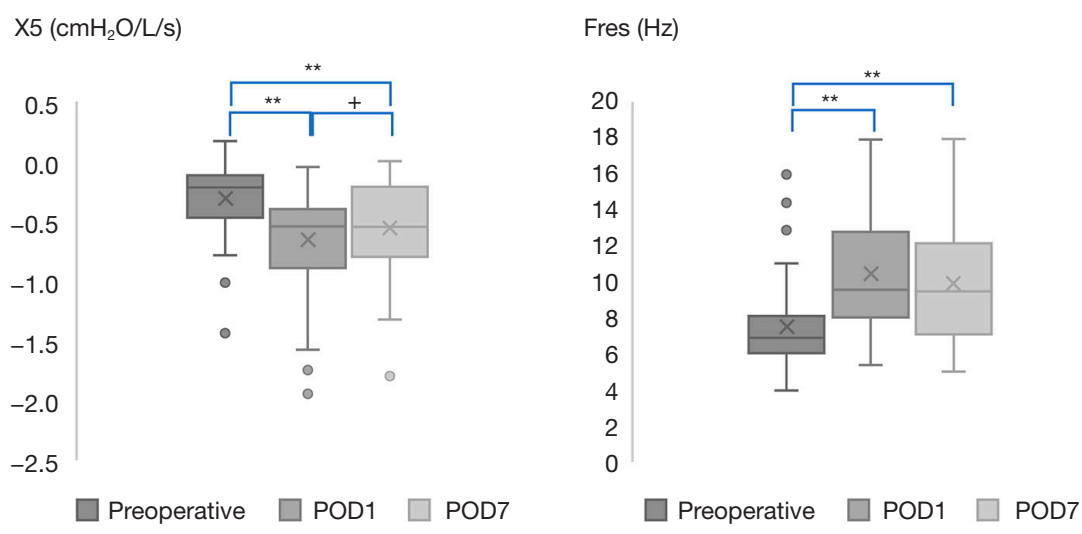

$\mathrm{ALX}\left(\mathrm{cmH}_{2} \mathrm{O} / \mathrm{L} / \mathrm{s} \times \mathrm{Hz}\right)$

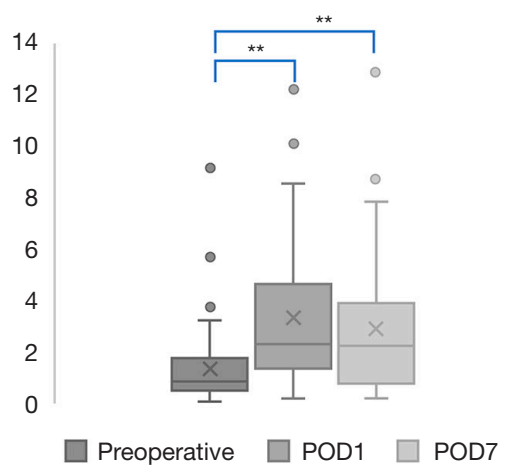

Figure 1 Changes in forced oscillatory parameters during the perioperative period. Values are presented as mean \pm standard deviation. After surgery, R5, R20, R5-R20, Fres, and ALX increased significantly, whereas X5 decreased. No significant changes were observed between POD1 and POD7 in any of the parameters. $\mathrm{x}$ : average; -: median. ${ }^{*}, \mathrm{P}<0.05 ;{ }^{*}, \mathrm{P}<0.01$ versus preoperative parameters.,$+ \mathrm{P}<0.05$ versus POD1. ALX, low-frequency reactance area; Fres, resonant frequency; Rrs, respiratory system resistance; R5 and R20, Rrs at 5 Hz and 20 Hz; R5-R20, the difference between R5 and R20; Xrs, respiratory system reactance; X5, Xrs at 5 Hz.

Table 3 Changes in forced oscillatory parameters during the perioperative period

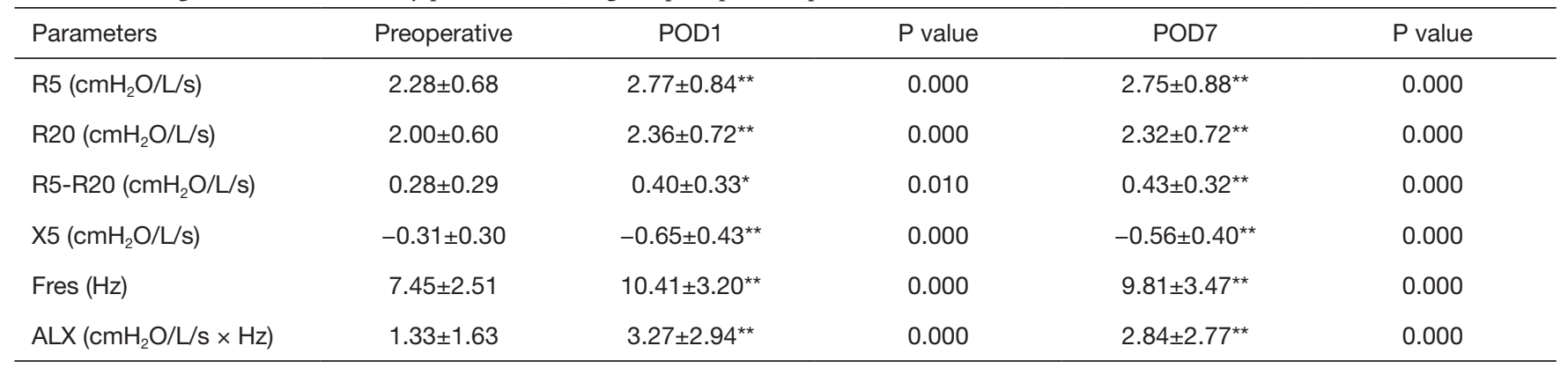

*, $\mathrm{P}<0.05$; **, $\mathrm{P}<0.01$ versus preoperative scores. ALX, low-frequency reactance area; Fres, resonant frequency; R5, respiratory system resistance at $5 \mathrm{~Hz}$; R20, respiratory system resistance at $20 \mathrm{~Hz}$; R5-R20, the difference between R5 and R20; X5, respiratory system reactance at $5 \mathrm{~Hz}$; POD, postoperative day. 

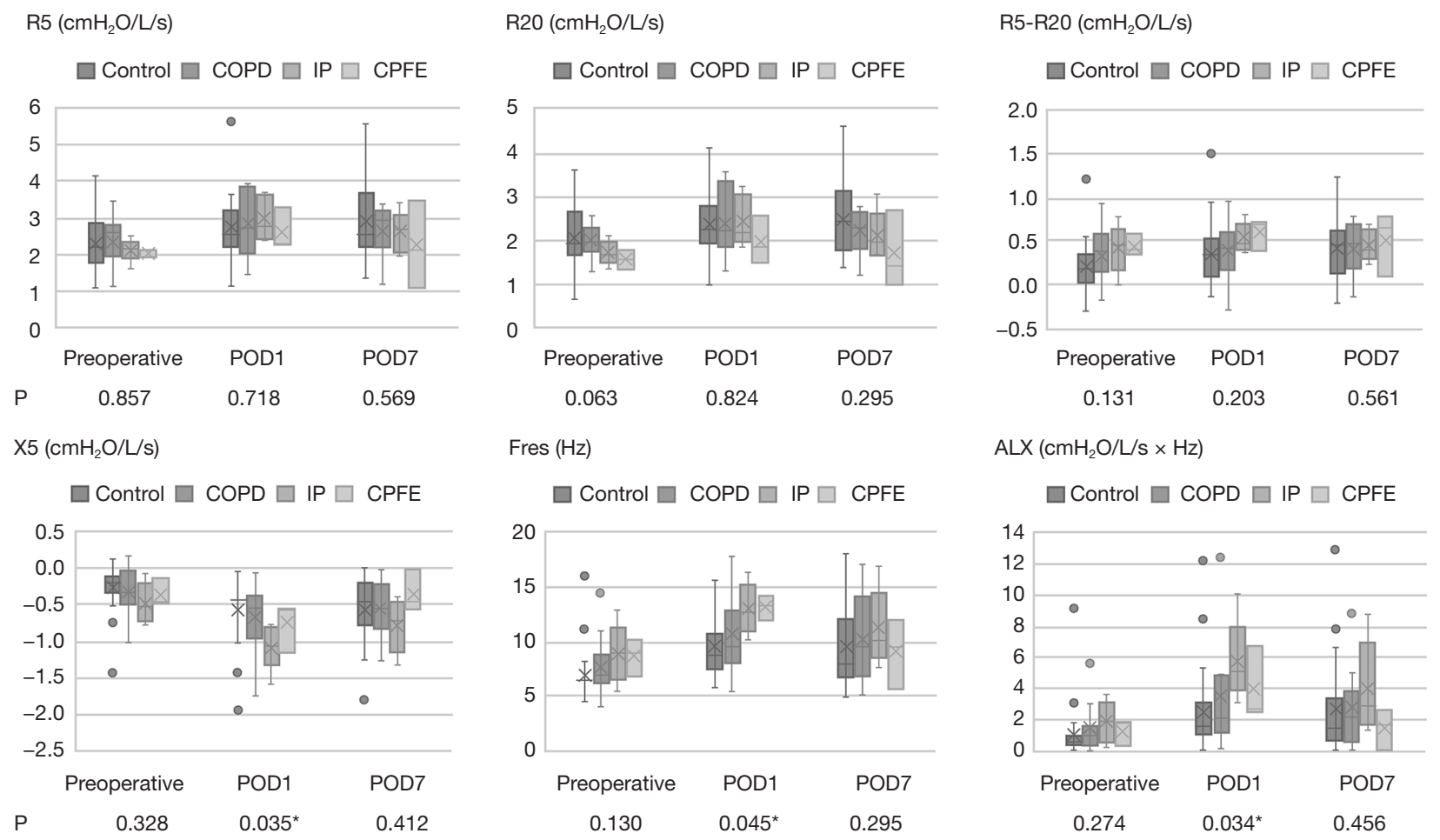

Figure 2 Changes in forced oscillatory parameters during the perioperative period in respiratory disease subgroups. Values are presented as mean \pm standard deviation. There was no significant difference in FOT measurements between the subgroups, but significant differences were noted in X5, Fres, and ALX on POD1. x: average; -: median. *, P<0.05, POD1 versus POD7. R5 and R20, Rrs at 5 Hz and 20 Hz; R5-R20, the difference between R5 and R20; ALX, low-frequency reactance area; CPFE, combined pulmonary fibrosis and emphysema; COPD, chronic obstructive pulmonary disease; Fres, resonant frequency; IP, interstitial pneumonia; X5, Xrs at 5 Hz.

$\left(\mathrm{FEV}_{1.0}\right), \% \mathrm{FEV}_{1.0}$, forced expiratory volume \% during the first second $\left.\left(\mathrm{FEV}_{1.0} \%\right)\right]$. Perioperative factors showing significant correlation with impedance included the number of resection segments, blood loss, body weight gain rate, and respiratory complications of CTCAE grade 1 and above. In contrast, there was no significant correlation of Zrs with the surgical approach, length of surgery, and excision site.

Many of the observed correlations were relatively weak. Factors showing a moderate correlation, with an absolute correlation coefficient $(\mathrm{R})$ value of 0.4 or more are described below.

\section{All clinical factors, $|\mathrm{R}| \geq \mathbf{0 . 4}$}

Age was positively correlated with the preoperative R5-R20 (R $=0.478$ ). Male sex and height were negatively correlated with the preoperative R5 and R20 (male sex: R $=-0.418,-0.643$, respectively; height: $\mathrm{R}=-0.460$ and -0.489 , respectively; Table 4). There was a relatively strong negative correlation of preoperative $\mathrm{VC}$ and $\mathrm{FEV}_{1.0}$ with the preoperative $\mathrm{R} 5$ and R20 (VC: $\mathrm{R}=-0.621$ and -0.571 , respectively; $\mathrm{FEV}_{1.0}$ : R $=-0.610$ and -0.529 , respectively; Table 4).

There was a negative correlation between the number of resection segments and R20 on POD1 $(\mathrm{R}=-0.445)$ and a positive correlation between blood loss and R5 and R5-R20 on POD1 ( $\mathrm{R}=0.465$ and 0.456 , respectively).

All respiratory complications, including atelectasis without treatment or medication, were positively correlated with R5-R20 and Fres on POD7 ( $\mathrm{R}=0.415$ and 0.441 , respectively) and negatively correlated with $\mathrm{X} 5(\mathrm{R}=-0.421)$ on POD7. Postoperative hypoxemia and cough for which antitussives were administered were positively and negatively correlated with Fres on POD1 $(\mathrm{R}=0.433$ and -0.459 , respectively). The correlation of $\mathrm{Zrs}$ with atelectasis, pneumonia, and sputum was insignificant $(|R| \geq 0.4)$.

\section{Discussion}

To the best of our knowledge, the Zrs in lung resection has 

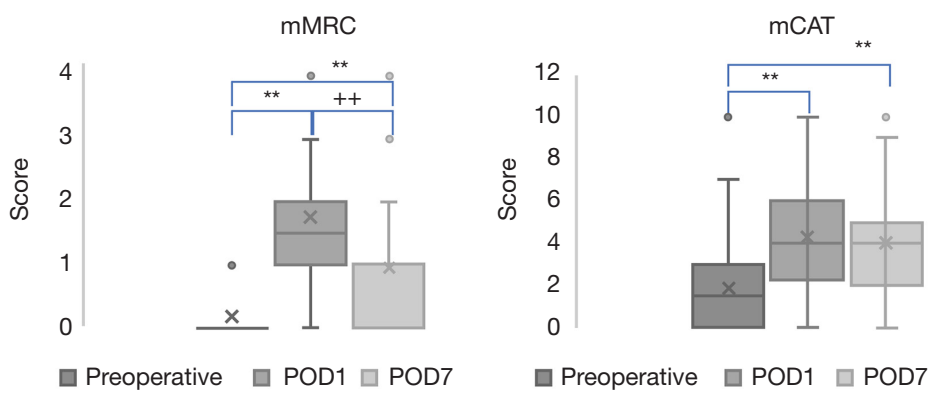

Figure 3 Changes in subjective symptoms' scores during the perioperative period. Values are presented as mean \pm standard deviation. After surgery, both the $\mathrm{mMRC}$ and mCAT scores increased. The mMRC score significantly improved from POD1 to POD7, whereas the mCAT score did not change. $\times$ : average; -: median. ** $\mathrm{P}<0.01$ versus preoperative scores; ++, $\mathrm{P}<0.01$, POD1 versus POD7. mCAT, modified COPD assessment test; COPD, chronic obstructive pulmonary disease; mMRC, modified Medical Research Council.

not been examined. This study's primary purpose was to clarify the change in Zrs during the perioperative period of lobectomy and examine the relationship of Zrs with clinical factors. After surgery, FOT parameters other than X5 significantly increased, whereas X5 decreased on POD1 and POD7. There were 29 combinations of clinical factors correlating with Zrs, but nearly half of those combinations had only a weak correlation.

Several studies have reported that FOT parameters correlate with spirometry $(17,18)$. Nikkuni and colleagues measured Zrs and spirometry preoperatively and 2 weeks after esophageal surgery and reported that changes in FVC and $\mathrm{FEV}_{1.0}$ were significantly correlated with changes in R5 (19). Consistently, we found that preoperative $\mathrm{VC}$ and $\mathrm{FEV}_{1.0}$ correlated with almost all preoperative Zrs parameters, suggesting that Rrs depends on the lung volume. In this study, postoperative spirometry was not measured because of the difficulty in obtaining accurate measurements due to the patients' postoperative pain and cough. Since lobectomy decreases $\mathrm{VC}$ and $\mathrm{FEV}_{1.0}$ according to the amount of resection, we consider that changes in Rrs were caused by a decrease in the lung volume. In addition, the following conditions may be present during the perioperative period: (I) airway obstruction due to increased sputum, (II) increased tissue resistance due to edematous changes in lung tissue and bronchi, (III) postoperative decrease in chest-wall compliance due to pain and chest closure, and (IV) uneven ventilation due to changes in intrathoracic pressure. The loss of lung volume and these conditions may have affected respiratory impedance. However, since there are many confounding factors, it may be necessary to examine it in combination with other evaluation factors, such as spirometry and computed tomography (CT).
Subjective symptoms are one of the most clinically important factors in assessing the usefulness of Zrs measurements before and after lung resection. Subjective symptom scores based on the mMRC and mCAT scores increased after surgery. However, while the mMRC score improved rapidly from POD1 to POD7, the mCAT score did not improve by POD7. After surgery, mMRC score, which shows only dyspnea on exertion, may have improved in a short period by removing the chest drainage tube. However, sputum and cough, which persisted, were also considered in the mCAT score; therefore, improvement may have been insufficient. In POD7, Zrs measurements, other than R5-R20, showed a relatively weak correlation with the mMRC score. Unfortunately, it was difficult to correlate subjective symptoms with $\mathrm{Zrs}$ because the mMRC score can be affected by postoperative complications.

This study found a positive correlation between intraoperative blood loss and R5 and R5-R20 on POD1. Rrs, especially R5, represents the airway diameter (1), which can be affected by edematous changes in the airways and bronchial obstruction with sputum or bloody sputum. The circulating plasma volume is usually decreased due to surgery and anesthesia, leading to edema (20-23), and increased bleeding increases intraoperative fluid volume and anesthesia time, resulting in increased edema. Therefore, it was considered that the intraoperative bleeding amount was correlated with R5 and R5-R20 on POD1. Improved weight gain on POD7 showed improved diuresis and edema, consistent with no correlation between R5 and R5R20 at this time point. Airway narrowing due to edema and sputum can cause respiratory complications, such as atelectasis, pneumonia, and hypoxemia. Thus, early detection by measuring Rrs before the appearance of 
Table 4 Significant correlations between forced oscillatory parameters and clinical factors

\begin{tabular}{|c|c|c|c|}
\hline Factors & Measured value & $\mathrm{R}$ & $P$ value \\
\hline \multicolumn{4}{|l|}{ Preoperative factors } \\
\hline Age & $\mathrm{R} 5-\mathrm{R} 2 \mathrm{O}_{\text {pre }}$ & $0.478^{\star \star}$ & 0.001 \\
\hline \multirow[t]{3}{*}{ Male sex } & $\mathrm{R} 5_{\text {pre }}$ & $-0.418^{\star \star}$ & 0.005 \\
\hline & $\mathrm{R} 20_{\text {pre }}$ & $-0.643^{\star \star}$ & 0.000 \\
\hline & $\mathrm{R} 5-\mathrm{R} 2 \mathrm{O}_{\text {pre }}$ & $0.340^{\star \star}$ & 0.024 \\
\hline \multirow[t]{2}{*}{ Height } & $\mathrm{R} 5_{\text {pre }}$ & $-0.460^{\star \star}$ & 0.002 \\
\hline & $\mathrm{R} 2 \mathrm{O}_{\text {pre }}$ & $-0.489^{\star \star}$ & 0.001 \\
\hline \multirow[t]{3}{*}{ B.I. } & $\mathrm{R} 5-\mathrm{R} 2 \mathrm{O}_{\text {pre }}$ & $0.355^{\star}$ & 0.018 \\
\hline & $X 5_{\text {pre }}$ & $-0.322^{*}$ & 0.033 \\
\hline & Fres $_{\text {pre }}$ & $0.337^{\star}$ & 0.025 \\
\hline \multicolumn{4}{|l|}{ Spirometry } \\
\hline \multirow[t]{5}{*}{ VC } & $\mathrm{R} 5_{\text {pre }}$ & $-0.621^{\star *}$ & 0.000 \\
\hline & $\mathrm{R} 2 \mathrm{O}_{\text {pre }}$ & $-0.571^{\star *}$ & 0.000 \\
\hline & $X 5_{\text {pre }}$ & $0.339^{*}$ & 0.025 \\
\hline & Fres $_{\text {pre }}$ & $-0.323^{\star}$ & 0.032 \\
\hline & $A L X_{\text {pre }}$ & $-0.303^{*}$ & 0.045 \\
\hline \multirow[t]{3}{*}{$\% \mathrm{VC}$} & $\mathrm{R} 5-\mathrm{R} 2 \mathrm{O}_{\text {pre }}$ & $-0.310^{\star}$ & 0.041 \\
\hline & $X 5_{\text {pre }}$ & $0.298^{\star}$ & 0.049 \\
\hline & Fres $_{\text {pre }}$ & $-0.305^{\star}$ & 0.044 \\
\hline \multirow[t]{3}{*}{$\mathrm{FEV}_{1.0}$} & $\mathrm{R} 5_{\text {pre }}$ & $-0.610^{\star \star}$ & 0.000 \\
\hline & $\mathrm{R} 2 \mathrm{O}_{\text {pre }}$ & $-0.529^{\star \star}$ & 0.000 \\
\hline & $\mathrm{R} 5-\mathrm{R} 2 \mathrm{O}_{\text {pre }}$ & $-0.347^{\star \star}$ & 0.009 \\
\hline$\% \mathrm{FEV}_{1.0}$ & $\mathrm{R} 5-\mathrm{R} 2 \mathrm{O}_{\text {pre }}$ & $-0.317^{\star \star}$ & 0.036 \\
\hline \multicolumn{4}{|l|}{ Perioperative factors } \\
\hline \multirow[t]{3}{*}{$\begin{array}{l}\text { Number of resection } \\
\text { segments }\end{array}$} & $\mathrm{R} 5_{\mathrm{POD} 1}$ & $-0.339^{\star}$ & 0.024 \\
\hline & $\mathrm{R} 20_{\mathrm{POD} 1}$ & $-0.445^{\star \star}$ & 0.002 \\
\hline & $\mathrm{R} 20_{\mathrm{POD} 7}$ & $-0.337^{\star}$ & 0.025 \\
\hline \multirow[t]{3}{*}{ Blood loss } & $\mathrm{R} 5_{\mathrm{POD} 1}$ & $0.465^{\star \star}$ & 0.001 \\
\hline & $\mathrm{R} 20_{\mathrm{POD} 1}$ & $0.329^{*}$ & 0.029 \\
\hline & $\mathrm{R} 5-\mathrm{R} 20_{\mathrm{POD} 1}$ & $0.456^{\star \star}$ & 0.002 \\
\hline \multirow[t]{3}{*}{$\begin{array}{l}\text { Body weight gain rate } \\
\text { (POD7) }\end{array}$} & $X 5_{\mathrm{POD} 7}$ & $0.326^{\star}$ & 0.031 \\
\hline & Fres $_{\mathrm{POD} 7}$ & $-0.384^{*}$ & 0.010 \\
\hline & $A L X_{P O D 7}$ & $-0.308^{*}$ & 0.042 \\
\hline
\end{tabular}

Table 4 (continued)
Table 4 (continued)

\begin{tabular}{|c|c|c|c|}
\hline Factors & Measured value & $\mathrm{R}$ & $P$ value \\
\hline \multicolumn{4}{|c|}{ Postoperative complications } \\
\hline \multirow{5}{*}{$\begin{array}{l}\text { Respiratory } \\
\text { complications }\end{array}$} & $\mathrm{R} 5_{\mathrm{POD} 7}$ & $0.361^{*}$ & 0.016 \\
\hline & $\mathrm{R} 5-\mathrm{R}^{2} \mathrm{P}_{\mathrm{POD} 7}$ & $0.415^{\star \star}$ & 0.005 \\
\hline & $X 5_{\mathrm{POD} 7}$ & $-0.421^{\star *}$ & 0.004 \\
\hline & Fres $_{\mathrm{POD} 7}$ & $0.441^{\star *}$ & 0.003 \\
\hline & $A L X_{\mathrm{POD} 7}$ & $0.376^{\star}$ & 0.011 \\
\hline Atelectasis & $\mathrm{R} 5-\mathrm{R} 20_{\mathrm{POD} 7}$ & $0.326^{*}$ & 0.031 \\
\hline \multirow[t]{2}{*}{ Hypoxemia (HOT) } & Fres $_{\mathrm{POD} 1}$ & $0.433^{\star *}$ & 0.003 \\
\hline & Fres $_{\mathrm{POD} 7}$ & $0.361^{*}$ & 0.016 \\
\hline \multirow{7}{*}{$\begin{array}{l}\text { Cough (need to take } \\
\text { antitussives) }\end{array}$} & $\mathrm{R} 5-\mathrm{R} 2 \mathrm{O}_{\text {pre }}$ & $-0.384^{*}$ & 0.010 \\
\hline & $\mathrm{R} 5-\mathrm{R} 2 \mathrm{O}_{\mathrm{POD} 1}$ & $-0.324^{*}$ & 0.032 \\
\hline & $\times 5_{\text {POD1 }}$ & $0.399^{* *}$ & 0.007 \\
\hline & Fres $_{\text {pre }}$ & $-0.300^{\star}$ & 0.048 \\
\hline & Fres $_{\mathrm{POD} 1}$ & $-0.459^{\star \star}$ & 0.002 \\
\hline & Fres $_{\mathrm{POD} 7}$ & $-0.317^{\star}$ & 0.036 \\
\hline & $A L X_{P O D 1}$ & $-0.373^{\star}$ & 0.013 \\
\hline
\end{tabular}

${ }^{*}, \mathrm{P}<0.05 ;{ }^{*}, \mathrm{P}<0.01$ (Pearson correlation analysis). ALX, lowfrequency reactance area; B.I., Brinkman index; CTCAE, Common Terminology Criteria for Adverse Events; FEV $_{1.0}$, forced expiratory volume in 1 second; $\% \mathrm{FEV}_{1.0}$, measured forced expiratory volume in 1 second/predicted forced expiratory volume in 1 second $\times 100$; VC, vital capacity; \%VC, measured vital capacity/predicted vital capacity $\times 100$; Fres, resonant frequency; HOT, home oxygen therapy; $\mathrm{R}$, correlation coefficient; $\mathrm{R} 5$, respiratory system resistance at $5 \mathrm{~Hz}$; R20, respiratory system resistance at $20 \mathrm{~Hz}$; R5-R20, the difference between $\mathrm{R} 5$ and $\mathrm{R} 20$; $\mathrm{X} 5$, respiratory system reactance at $5 \mathrm{~Hz}$; POD, postoperative day.

infiltrative shadows and symptoms on chest radiography enables early therapeutic intervention that may contribute to a better prognosis.

We initially thought it would be beneficial for patients if we could predict or diagnose postoperative complications early by measuring Zrs. However, in reality, few postoperative complications required treatment, and many were insignificant, so the expected results were not obtained. However, on POD1, Fres was moderately correlated with hypoxemia and cough requiring antitussives. In particular, 3 out of 4 patients with postoperative hypoxemia had a history of 
IP. Considering that Fres is a marker of pulmonary fibrosis in IP $(8,9)$, the increase in Fres in the early postoperative period may predict hypoxemia in patients with IP and useful for early intervention after surgery. Although the number of patients in each subgroup of respiratory disease was small, the subgroup analysis results of Zrs provided limited support to this hypothesis. Fortunately, no postoperative acute exacerbation of IP was observed in this study, but the fatality rate is high when it develops, and early diagnosis and treatment are important. In this regard, measuring Zrs can be advantageous.

This study has several limitations. First, only univariate analysis has been performed, and confounding factors contributing to changes in FOT parameters cannot be excluded. Zrs strongly correlates with physiological factors such as age, sex, and height; however, the prediction equation itself has not been established, and there were no specific reference values for MostGraph $(1,24,25)$, so it is difficult to evaluate it by comparing simple numerical values. Another bias is that different individuals feel pain differently, and chest tube removal timing also differs between patients. Second, this study was limited to lobectomy and included only cases with a pulmonary function that could tolerate lobectomy, and thus cases with a poor general condition in which lobectomy could not be performed were not included. As preoperative comorbidities vary widely, there may be no significant correlation between preoperative comorbidities and perioperative Zrs changes. Finally, this study was conducted in a single-center, and the sample size was small.

In conclusion, this study clarified changes in Zrs during the perioperative period of radical lobectomy for lung cancer and the correlation between Zrs and other clinical factors. Zrs parameters were different postoperatively, but its measurement did not predict or diagnose early postoperative complications. However, some Zrs parameters were correlated with clinical factors associated with the clinical course. In particular, Fres on POD1 was correlated with hypoxia, which may be an important predictor of early detection of hypoxemia and acute exacerbation in patients with IP. There are many confounding factors, and the exact clinical factor associated with a specific $\mathrm{Zrs}$ parameter remains unclear. Eliminating confounders is difficult; however, the postoperative course can be further enhanced by analyzing more cases and comparing changes in Zrs over a longer period using conventional spirometry, combined with anatomical evaluations by CT. Further, because MostGraph could measure Zrs even in the early postoperative period, we expect that MostGraph can be used in the future for evaluating respiratory function in the early postoperative period instead of spirometry.

\section{Acknowledgments}

We would like to thank Editage (www.editage.com) for English language editing.

Funding: None.

\section{Footnote}

Reporting Checklist: The authors have completed the STROBE reporting checklist. Available at http://dx.doi. org/10.21037/jtd-20-3090

Data Sharing Statement: Available at http://dx.doi. org/10.21037/jtd-20-3090

Peer Reviewv File: Available at http://dx.doi.org/10.21037/jtd20-3090

Conflicts of Interest: All authors have completed the ICMJE uniform disclosure form (available at http://dx.doi. org/10.21037/jtd-20-3090). The authors have no conflicts of interest to declare.

Ethical Statement: The authors are accountable for all aspects of the work in ensuring that questions related to the accuracy or integrity of any part of the work are appropriately investigated and resolved. The study was conducted in accordance with the Declaration of Helsinki (as revised in 2013). The study was approved by the ethics board of Shiga University of Medical Science (NO.: R2017185; December 25, 2017) and written informed consent was obtained from each participant.

Open Access Statement: This is an Open Access article distributed in accordance with the Creative Commons Attribution-NonCommercial-NoDerivs 4.0 International License (CC BY-NC-ND 4.0), which permits the noncommercial replication and distribution of the article with the strict proviso that no changes or edits are made and the original work is properly cited (including links to both the formal publication through the relevant DOI and the license). See: https://creativecommons.org/licenses/by-nc-nd/4.0/.

\section{References}

1. Shirai T, Kurosawa H. Clinical Application of the Forced 
Oscillation Technique. Intern Med 2016;5 5:559-66.

2. Oostveen E, Macleod D, Lorino H, et al. The forced oscillation technique in clinical practice: methodology, recommendations and future developments. Eur Respir J 2003;22:1026-41.

3. Shi Y, Aledia AS, Galant SP, et al. Peripheral airway impairment measured by oscillometry predicts loss of asthma control in children. J Allergy Clin Immunol 2013;131:718-23.

4. Bickel, S, Popler J, Lesnick B, et al. Impulse oscillometry. Interpretation and practical applications. Chest 2014;146:841-7.

5. Mori K, Shirai T, Mikamo M, et al. Colored 3-dimenssional analyses of respiratory resistance and reactance in COPD and asthma. COPD 2011;8:456-63.

6. Kanda S, Fujimoto K, Komatsu Y, et al. Evaluation of respiratory impedance in asthma and COPD by impulse oscillation system. Intern Med 2010;49:23-30.

7. Gonem S, Natarajan S, Desai D, et al. Clinical significance of small airway obstruction markers in patients with asthma. Clin Exp Allergy 2014;44:499-507.

8. Fujii M, Shirai T, Mori K, et al. Inspiratory resonant frequency of forced oscillation technique as a predictor of the composite physiologic index in interstitial lung disease. Respir Physiol Neurobiol 2015;207:22-7.

9. Mori K, Shirai T, Mikamo M, et al. Respiratory mechanics measured by forced oscillation technique in combined pulmonary fibrosis and emphysema. Respir Physiol Neurobiol 2013;185:235-40.

10. Bestall JC, Paul EA, Garrod R, et al. Usefulness of the Medical Research Council (MRC) Dyspnoea Scale as a Measure of Disability in Patients With Chronic Obstructive Pulmonary Disease. Thorax 1999;54:581-6.

11. Munari AB, Gulart AA, Santos KD, et al. Modified Medical Research Council Dyspnea Scale in GOLD Classification Better Reflects Physical Activities of Daily Living. Respir Care 2018;63:77-85.

12. Tsuda T, Suematsu R, Kamohara K, et al. Development of the Japanese Version of the COPD Assessment Test. Respir Investig 2012;50:34-9.

13. Mackay AJ, Donaldson GC, Patel ARC, et al. Usefulness of the Chronic Obstructive Pulmonary Disease Assessment Test to Evaluate Severity of COPD Exacerbations. Am J Respir Crit Care Med 2012;185:1218-24.

14. Jones PW, Harding G, Berry P, et al. Development and First Validation of the COPD Assessment Test. Eur Respir J 2009;34:648-54.

15. Brierley JD, Gospodarowicz MK, Wittekind C. edsitors.
TNM Classification of Malignant Tumours. 8th edition. NJ: Wiley-Blackwell, 2016.

16. National Cancer Institute [Internet]. Common Terminology Criteria for Adverse Events (CTCAE) [cited 2020 October 7]. Available onine: https:// ctep.cancer.gov/protocolDevelopment/electronic applications/ctc.htm

17. Yamamoto S, Miyoshi S, Katayama H, et al. Use of the forced-oscillation technique to estimate spirometry values. Int J Chron Obstruct Pulmon Dis 2017;12:2859-68.

18. Isobe Z, Hara K, Maeno T. Respiratory impedance measuring by MostGraph-01 is affected by obesity. Arerugi 2015;64:1254-60.

19. Etsuhiro N, Ritsuko A, Emiri M, et al. Evaluation of respiratory function in patients with esophageal cancer who underwent endoscopic esophagectomy with gastric tube reconstruction-significance of forced oscillation technique. The Journal of the Japan Society for Respiratory Care and Rehabilitation 2017;27:41-7.

20. Iijima T. The recent advancement of the concept of perioperative fluid therapy. The Journal of the Japan Society for Respiratory Care and Rehabilitation 2012;19:578-85.

21. Maddox DA, Price DC, Rector FC Jr. Effects of Surgery on Plasma Volume and Salt and Water Excretion in Rats. Am J Physiol 1977;233:F600-6.

22. Norberg A, Han RG, Li H, et al. Population Volume Kinetics Predicts Retention of $0.9 \%$ Saline Infused in Awake and Isoflurane-Anesthetized Volunteers. Anesthesiology 2007;107:24-32.

23. Chan ST, Kapadia CR, Johnson AW, et al. Extracellular fluid volume expansion and third space sequestration at the site of small bowel anastomoses. Br J Surg 1983;70:36-9.

24. Shiota S, Katoh M, Fujii M, et al. Predictive Equations and the Reliability of the Impulse Oscillatory System in Japanese Adult Subjects. Respirology 2005;10:310-5.

25. Abe Y, Shibata Y, Igarashi A, et al. Reference Values of MostGraph Measures for Middle-Aged and Elderly Japanese Individuals Who Participated in Annual Health Checkups. Respir Investig 2016;54:148-55.

Cite this article as: Kaku R, Yoden M, Shiratori T, Hayashi K, Okamoto K, Oshio Y, Nakano Y, Hanaoka J. Perioperative changes in respiratory impedance in lobectomy and their clinical impact. J Thorac Dis 2021;13(3):1347-1357. doi: 10.21037/ jtd-20-3090 